Corrigendum

\title{
Corrigendum to "Propofol Attenuates Small Intestinal Ischemia Reperfusion Injury through Inhibiting NADPH Oxidase Mediated Mast Cell Activation"
}

\author{
Xiaoliang Gan, ${ }^{1,2}$ Dandan Xing, ${ }^{1}$ Guangjie Su, ${ }^{1}$ Shun Li, ${ }^{1}$ Chenfang Luo, ${ }^{1}$ Michael G. Irwin, ${ }^{3}$ \\ Zhengyuan Xia, ${ }^{3}$ Haobo $\mathrm{Li}^{3}{ }^{3}$ and Ziqing $\mathrm{Hei}^{1}$ \\ ${ }^{1}$ Department of Anesthesiology, The Third Affiliated Hospital, Sun Yat-sen University, Guangzhou 510630, China \\ ${ }^{2}$ Zhongshan Ophthalmic Center, Department of Anesthesiology, Sun Yat-sen University, Guangzhou 510060, China \\ ${ }^{3}$ Department of Anesthesiology, University of Hong Kong, Hong Kong \\ Correspondence should be addressed to Haobo Li; haoboli@hku.hk and Ziqing Hei; heiziqing@sina.com \\ Received 6 March 2017; Accepted 12 March 2017; Published 14 August 2017 \\ Copyright (C) 2017 Xiaoliang Gan et al. This is an open access article distributed under the Creative Commons Attribution License, \\ which permits unrestricted use, distribution, and reproduction in any medium, provided the original work is properly cited.
}

In the article titled "Propofol Attenuates Small Intestinal Ischemia Reperfusion Injury through Inhibiting NADPH Oxidase Mediated Mast Cell Activation" [1], the $\alpha$-tubulin samples in Figures 5(g) and 5(h) should have included nine samples; however, due to an error during the production process, only seven samples appeared. Also, the legends of figures $5 \mathrm{~A}$ and $5 \mathrm{~B}$ were reversed. The corrected figures and legend are as follows. 


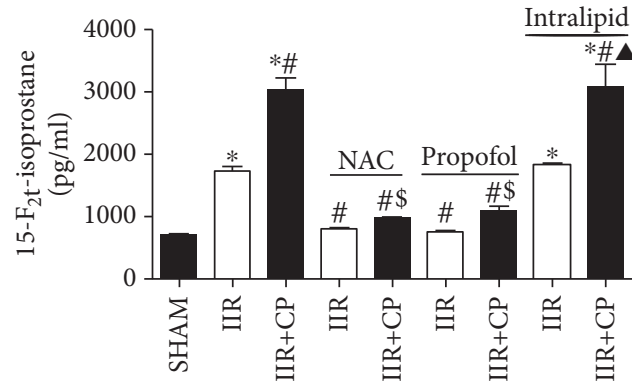

(a)
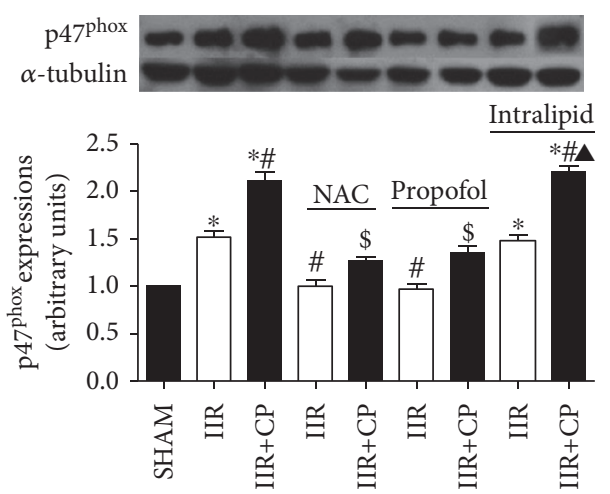

(c)

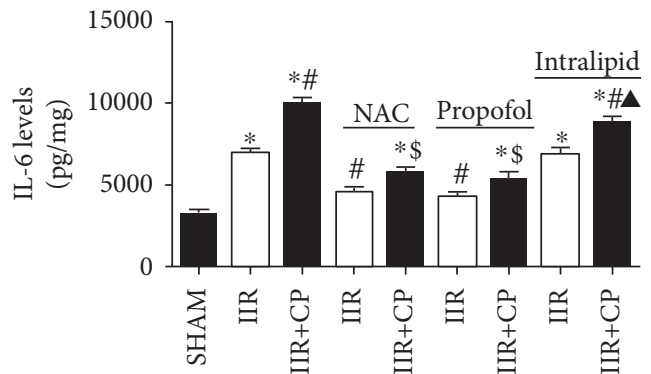

(e)

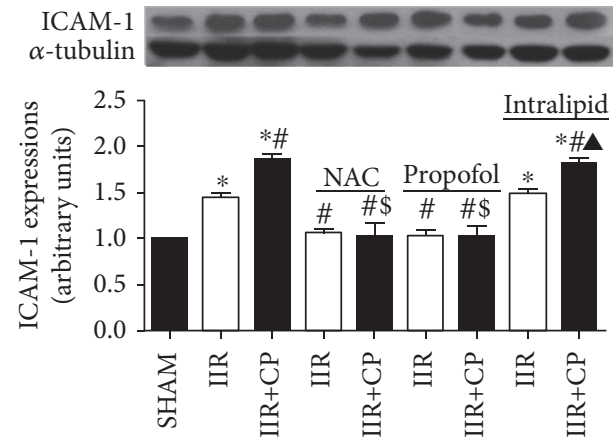

(g)

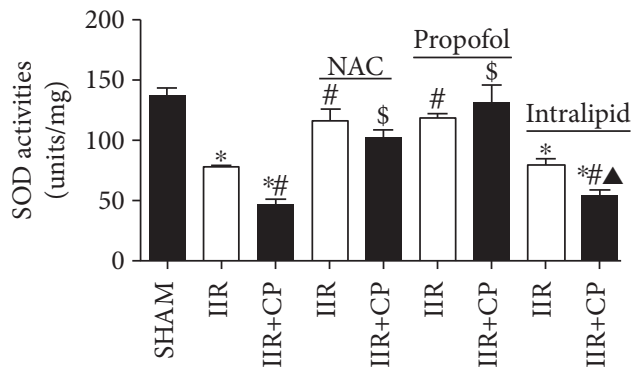

(b)

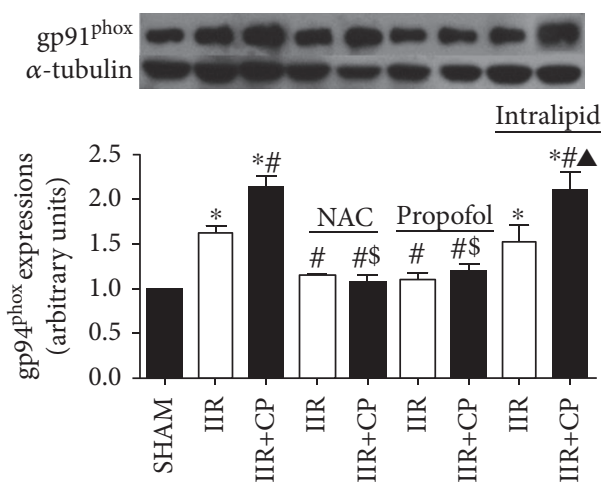

(d)

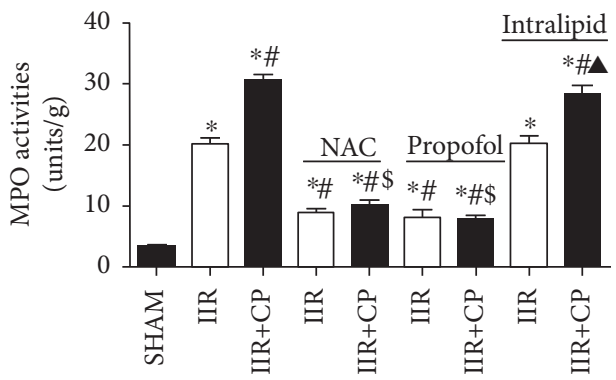

(f)

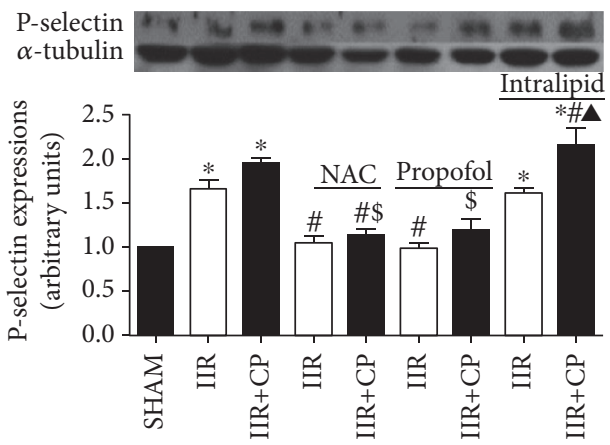

(h)

FIGURE 5: Changes of SOD activities, $15-\mathrm{F}_{2 \mathrm{t}}$-isoprostane contents, $\mathrm{p} 47^{\text {phox }}$ protein expression, gp91 ${ }^{\text {phox }}, \mathrm{P}$-selectin, and ICAM-1 protein expressions, IL-6 levels, and MPO activities in intestine mucosa after IIR injury. SHAM group (Sham-operated group), IIR group (75 min intestinal ischemia and $2 \mathrm{~h}$ reperfusion), and IIR + CP group (IIR group + compound 48/80 $1 \mathrm{mg} / \mathrm{kg}$ ) in the absence or presence of NAC $(0.5 \mathrm{~g} / \mathrm{kg})$, propofol $(50 \mathrm{mg} / \mathrm{kg})$, intralipid $(50 \mathrm{mg} / \mathrm{kg})$. (a) $15-\mathrm{F}_{2 \mathrm{t}}$-isoprostane contents in intestine $(n=6$, except $n=4$ in IIR + CP group). (b) SOD activities (c) and (d) p47 $7^{\text {phox }}$ and gp91 ${ }^{\text {phox }}$ protein expressions, respectively $(n=3)$, (e) and (f) IL-6 levels and MPO activities in intestinal mucosa $(n=6$, except $n=4$ in IIR + CP group). (g) and (h) ICAM-1 and P-selectin protein expressions, respectively $(n=3)$. Results are expressed as mean \pm SEM. ${ }^{*} P<0.05$ versus SHAM group, ${ }^{\sharp} P<0.05$ versus IIR group, ${ }^{\$} P<0.05$ versus IIR + CP group, ${ }^{\&} P<0.05$ versus IIR with NAC pretreated group, ${ }^{\wedge} P<0.05$ versus IIR with propofol pretreated group, and ${ }^{\Delta} P<0.05$ versus IIR with intralipid pretreated group. 


\section{Reference}

[1] X. Gan, D. Xing, G. Su et al., "Propofol attenuates small intestinal ischemia reperfusion injury through inhibiting NADPH oxidase mediated mast cell activation," Oxidative Medicine and Cellular Longevity, vol. 2015, Article ID 167014, 15 pages, 2015. 


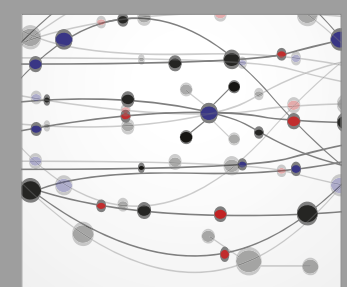

The Scientific World Journal
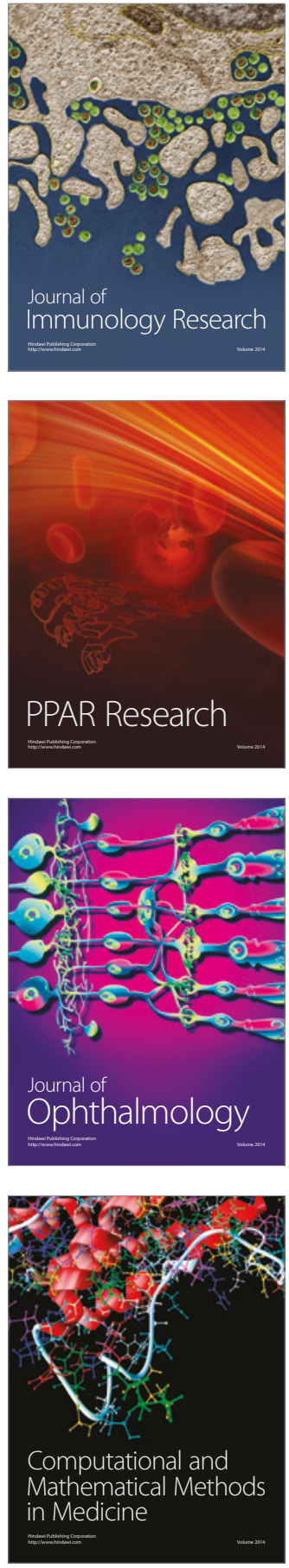

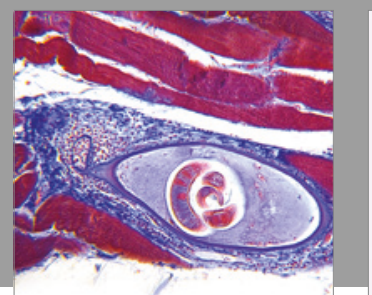

Gastroenterology Research and Practice
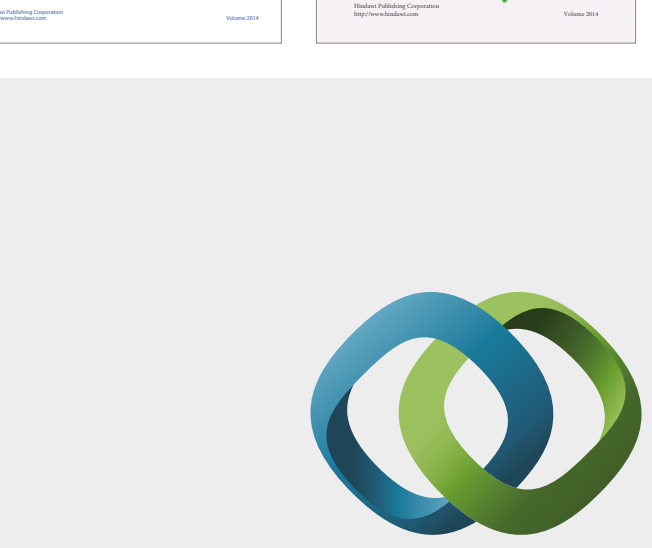

\section{Hindawi}

Submit your manuscripts at

https://www.hindawi.com
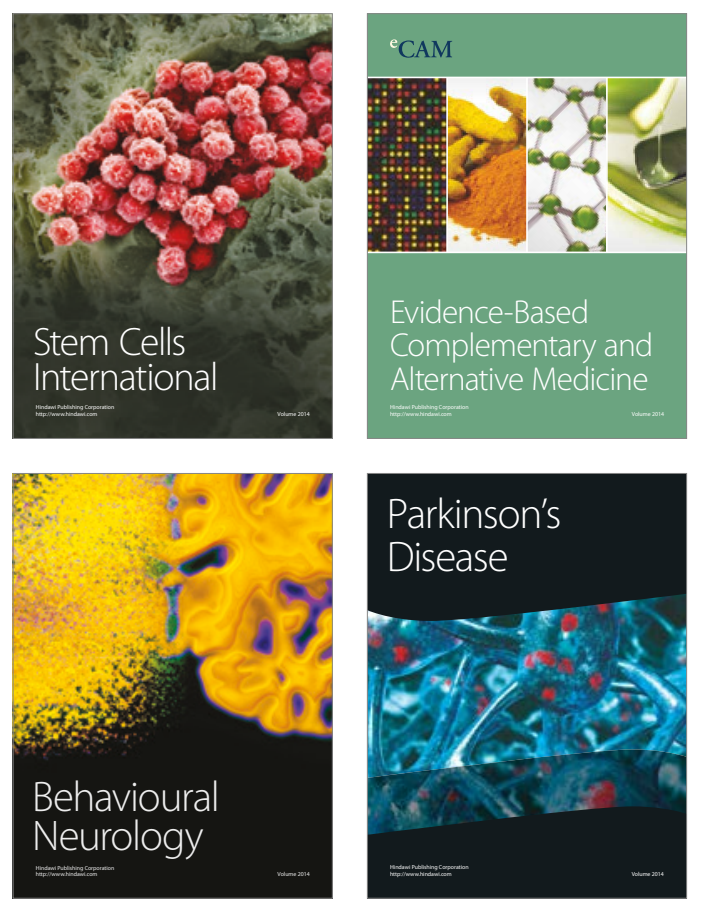
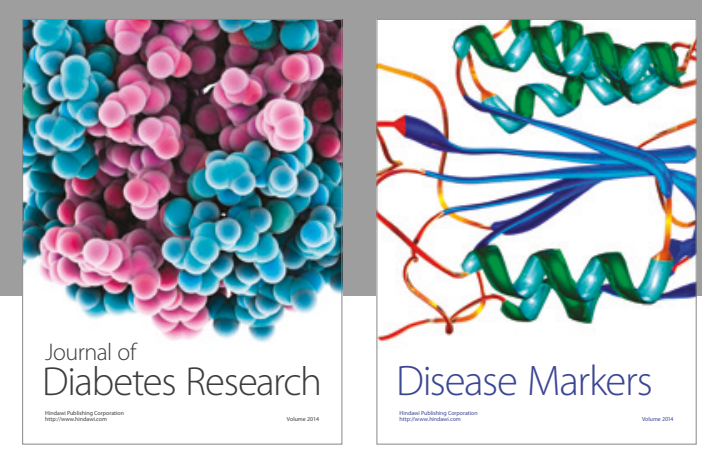

Disease Markers
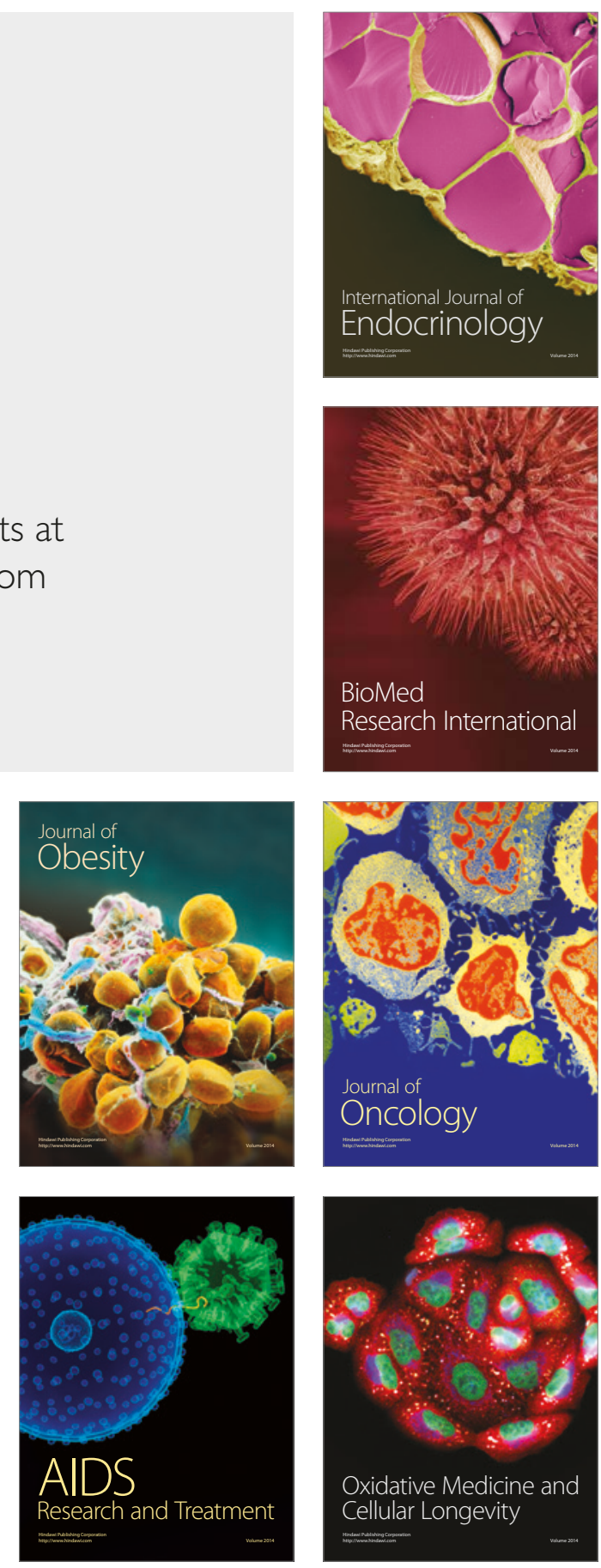